\title{
Melatonin enhanced bexarotene efficacy in experimental mammary carcinogenesis
}

\author{
P. ORENDAS ${ }^{1, *}$, P. KUBATKA ${ }^{2,5}, K^{2}$ KAJO ${ }^{3,4}$, N. STOLLAROVA ${ }^{5}$, M. KASSAYOVA ${ }^{1}$, B. BOJKOVA ${ }^{1}$, M. PEC ${ }^{2,5}$, V. NOSAL ${ }^{6}$, T. KISKOVA ${ }^{1}$, \\ K. ZIHLAVNIKOVA², R. KARSNAKOVA ${ }^{1}$
}

\begin{abstract}
${ }^{1}$ Department of Animal Physiology, Institute of Biology and Ecology, Faculty of Science, P.J. Šafárik University, Moyzesova 11, 04167 Košice, Slovak Republic; '2Department of Medical Biology, Jessenius Faculty of Medicine, Comenius University, Malá Hora 4, 03601 Martin, Slovak Republic; ${ }^{3}$ Department of Pathology, Slovak Medical University and St. Elisabeth Oncology Institute, Heydukova 10, 81108 Bratislava; ${ }^{4}$ BB Biocyt, Diagnostic Centre, Ltd., Nám. L. Svobodu 1, 97401 Banská Bystrica, Slovak Republic; ${ }^{5}$ Department of Biology and Ecology, Faculty of Education, Catholic University in Ružomberok, Hrabovská cesta 1, 03401 Ružomberok, Slovak Republic; ${ }^{6}$ Clinic of Neurology, Jessenius Faculty of Medicine, Comenius University (in University Hospital in Martin) Kollárova 2, 03659 Martin, Slovak Republic
\end{abstract}

*Correspondence: peter.orendas@upjs.sk

Received November 25, 2011 / Accepted March 7, 2012

\begin{abstract}
The aim of this paper was to test lower, safe bexarotene dose administered alone and in combination with melatonin to improve its efficacy. Mammary carcinogenesis was induced by N-methyl-N-nitrosourea in female Sprague-Dawley rats, administered in two doses intraperitoneally between 42.-54. postnatal days and chemoprevention was initiated 7 days prior to first N-methyl-N-nitrosourea injection and lasted 15 weeks. Bexarotene, particularly in combination with melatonin decreased mammary tumor incidence and frequency with a shift from poorly to well differentiated carcinomas. Bexarotene alleviated glycaemia and liver/heart muscle glycogen concentration decreased as well as liver/thymus malondialdehyde increased in comparison with control group.

The combination of bexarotene and melatonin is therefore beneficial in preventive-curative model of experimental mammary carcinogenesis and may be applied in oncological practice as such.
\end{abstract}

Key words: mammary carcinogenesis, female rats, bexarotene, melatonin, prevention

Retinoids act through two intracellular receptors of steroid receptor superfamily - retinoic acid receptors (RAR) and retinoid X receptors (RXR). RAR homodimers or RARRXR heterodimers are transcription factors controlling cell proliferation and differentiation. Furthermore, RAR-RXR heterodimers are ligands for numerous nuclear hormone receptors.

RAR ligands are known to suppress carcinogenesis: retinylacetate decreased tumor incidence in 7,12-dimethylbenz(a)anthracene (DMBA) - induced mammary carcinogenesis in female rats $[1,2]$, but had little efficacy in $\mathrm{N}$-methyl-N-nitrosourea (NMU) model which, however, was improved with simultaneous melatonin (MEL) administration [3]. Another retinoid fenretinide (N-4-hydroxyphenylretinamide, 4-HPR) was effective in numerous experimental tumor model prevention, but Moon et al. [4] reported high toxicity of 4-HPR (frequent liver damage, high triacylglycerolemia and skin lesions). RXR agonists - rexinoids show similar efficacy in tumor prevention [5] and treatment [6]. Selective RXR agonist bexarotene (BEXA) is the most frequently used rexinoid in clinical practice [7]. Bexarotene exerts preventive and treatment effects through cell cycle inhibition, apoptosis and differentiation induction [8]. Its administration, both preclinical and clinical, is not without side effects, metabolic disturbances, particularly hypertriacylglycerolemia were reported [6] .

Metabolic changes in tumor host do not reflect just metabolic alterations in tumor tissue; in experimental carcinogenesis metabolic alterations after carcinogen administration were recorded both in tumor-bearing and non-tumor bearing animals. Decrease of insulinemia (and glycaemia) is the hallmark of carbohydrate metabolism in cancer disease. The liver glycogen decreases and serum concentration of contrainsular hormones and IGF-1 increases. In addition carcinogen administration predominantly inhibits fatty acid oxidation and lipogenesis while lipolysis alterations are negligible $[9,10]$. Cancer progression is also associated with protein degradation 
and cachexia [11]. Typically carcinogenesis is also accompanied by increase in reactive oxygen products formation with concomitant tissue antioxidative capacity decrease [14].

MEL is one of the oldest and most uniform molecules in living organisms with pleiotropic functions. MEL acts as potent antioxidant, regulates circadian rhythms and reproduction and contributes to general fitness. Reactive oxygen species (ROS) - scavenging abilities, antiinflammatory, proapoptotic, and antiangiogenic activities predestine MEL as "natural" oncostatic substance. MEL is effective particularly in colorectal and mammary carcinogenesis prevention. MEL inhibits experimental mammary carcinogenesis through various mechanisms including estrogen receptor modulation, prolactin antagonism and liver fatty acid metabolism inhibition $[12,13]$. In female rats, MEL inhibits mammary tumor growth alone and in combination with other substances in vivo [14]. MEL has also been used in adjuvant chemotherapy in some human neoplasms [15].

The aim of our work was to analyse the effect of relatively low BEXA dose administered alone and in combination with MEL in preventive-curative mammary carcinogenesis model in Sprague-Dawley rats. We decided to evaluate tumor growth and selected serum and tissue metabolic parameters.

\section{Material and methods}

Female rats of Sprague-Dawley strain obtained from Germany (distribution by An-Lab, Prague, Czech Republic) aged 33-35 days were adapted to standard vivarium conditions with temperature $23 \pm 2^{\circ} \mathrm{C}$, relative humidity $60-70 \%$, artificial regimen light:dark $=12: 12 \mathrm{~h}$, with lights on from 7:00 h (light intensity 150 lux per cage).

The animals were fed Ssniff diet (Soest, Germany) and drank tap water ad libitum. Mammary carcinogenesis was induced by NMU (Sigma, Deisenhofen, Germany). NMU was administered intraperitoneally in two doses, each per $50 \mathrm{mg} / \mathrm{kg}$ b.w., between $42^{\text {th }}-54^{\text {th }}$ postnatal days (with a sevenday interval between doses). NMU was freshly prepared by dissolving in isotonic saline solution (the average volume per animal was $0.5 \mathrm{ml}$ ). BEXA (Eisai Ltd., London, Great Britain) was administered per os, starting 7 days before and ending 15 weeks after the first NMU dose in a concentration of 26.7 $\mathrm{mg} / \mathrm{kg}$ b.w. 3 days a week (Monday, Wednesday, Friday). MEL (Sigma, Deisenhofen, Germany) was applied daily, starting 7 days before and ending 15 weeks after the first NMU dose, in drinking water $(20 \mu \mathrm{g} / \mathrm{ml})$ from 15:00 to 8:00 (from 8:00 to 15:00 animals drank tap water without melatonin). The solution was freshly prepared three times a week. Twenty $\mathrm{mg}$ of the substance were diluted in $0.4 \mathrm{ml}$ of $30 \%$ ethanol and mixed up with tap water to the desired volume. The animals were divided into four groups: 1 . CONT - control group, 17 animals without chemoprevention but with carcinogen administration, 2. BEXA - 17 animals with carcinogen administration and BEXA chemoprevention, 3. BEXA+MEL - 17 animals with carcinogen administration and BEXA and MEL chemopreven- tion, 4. INT - 19 intact animals without chemoprevention and carcinogen administration. The animals were weekly weighed and investigated in order to record the incidence, number, location, and size of tumors. Food and water intake was recorded in $2 \mathrm{nd}, 4 \mathrm{th}, 7 \mathrm{th}, 9 \mathrm{th}, 11 \mathrm{th}$, and 14th week of the experiment. In the last week of the experiment all animals were sacrificed by quick decapitation and final investigation was performed: inspection of body organs, mammary tumor excision and size measurement (length, width). Tumor samples were preserved in $10 \%$ formalin solution for histopathological investigation. The tumors were classified according to the criteria for the classification of rat mammary tumors [16] with an additional parameter - carcinoma differentiation grade. Malignant tumor samples were divided into low-grade (LG) and high-grade (HG) carcinomas. The criteria for categorization were chosen according to the standard diagnostic patterns and include: solidization, cell atypia, mitotic activity index, and necrosis.

As $H G$ carcinomas were considered tumors with $\geq 2$ positive criteria, LG carcinomas were tumors with $\leq 1$ positive criterium. Positive solidization was considered if $>30 \%$ of tumor sample displayed solid growth, high mitotic activity index was recorded when $>10$ mitoses were observed in 10 high power fields and necrosis was determined by the presence of comedo (not infarct). Selected parameters of lipid and carbohydrate metabolism were analysed: serum concentration of triacylglycerols (TAG), cholesterol $(\mathrm{CH})$, phospholipids (PL), corticosterone (CST), and glucose (GLU); liver concentration/content of TAG, $\mathrm{CH}$, malondialdehyde (MDA, a lipid peroxidation marker), PL, and glycogen (GLY); heart muscle concentration/content of GLY, thymus concentration/content of MDA. The concentration of PL was determined from the lipid phosphorus by Bartlett's method [17], total $\mathrm{CH}$ according to Zlatkis et al. [18], GLY according to Roe and Dailey [19], MDA was determined using a reaction with thiobarbituric acid [20], TG and GLU concentrations were determined by commercial sets (Pliva-Lachema), CST was measured using fluorimetry according to Guillemin et al. [21]. Statistical evaluation of selected mammary carcinogenesis parameters, selected parameters of lipid and carbohydrate metabolism and body mass, food, and water intake were evaluated by a combination of non-parametric and parametric tests. Tumor incidence was evaluated by Mann-Whitney U-test, other parameters by oneway analysis of variance or Kruskal-Wallis test. Tumor volume was calculated according to the formula: $\mathrm{V}\left(\mathrm{mm}^{3}\right)=\pi \times \mathrm{S}_{1}{ }^{2} \times \mathrm{S}_{2}$ / 12; $\left(\mathrm{S}_{1}<\mathrm{S}_{2}\right), \mathrm{S} 1$ and $\mathrm{S} 2$ are tumor diameters $(\mathrm{S} 1<\mathrm{S} 2)$.

Experiment was approved by the State Veterinary and Food Administration of Slovak Republic by accreditation No. Ro2819/09-221.

\section{Results}

BEXA administration decreased mammary tumor incidence in preventive-curative experimental mammary carcinogenesis model but this was significant only in combination with melatonin (BEXA+MEL). BEXA alone and 
in combination with MEL considerably decreased tumor frequency per group when compared to the CONT group (Tab 1). Total tumor number in the CONT group was 36 and decreased to 13 in the BEXA and to 8 in the BEXA+MEL groups. We observed mainly malignant tumors, particularly the cribriform and the cribriform-papillary type. In contrast, only two benign tumors were found (in the BEXA group). Markedly more heterogeneous spectrum of carcinomas (with occurrence of comedo type) in the control group compared to treated groups was observed. The presence of more homogeneous tumor types with dominat pure cribriform lesions in the group BEXA+MEL was found (Tab 2). Carcinomas in the control group were characterized by lower degree of differentiation (predominant high grade tumors) with the signs of solid growth, higher cellular atypia and mitotic activity. Detailed cytologic assessment of invasive lesions (poorly differentiated HG tumor or well-differentiated LG tumor) revealed favourable HG:LG ratio in the BEXA (4:7) and in the BEXA+MEL (3:5) groups in comparison with the CONT group (21:15). No animals died during the experiment and no macroscopic tissue lesions were found by autopsy.
Food intake between 2nd-9th week in the CONT group was decreased in comparison with the INT rats. BEXA administration (alone and in combination with MEL) only decreased food intake in 14 th week and water intake only in 2 nd week of experiment as compared to the CONT group. The body mass gain in the CONT group was lower in comparison with the INT group and was not altered by BEXA or BEXA+MEL administration (not shown).

While glycaemia was lower in the CONT group when compared to the INT, serum lipid parameters remained unaltered. Liver TAG and $\mathrm{CH}$ content in the CONT group was decreased with no effect of BEXA and BEXA+MEL administration. Liver $\mathrm{PL}$ content in the CONT group was lower and rose in groups with chemoprevention. Similarly heart muscle glycogen content in the CONT group was decreased and recovered with the use of chemopreventives. Lipid peroxidation in liver and thymus (measured by concentration of MDA) increased in the CONT group, BEXA administration decreased it which was more prominent in BEXA+MEL group where the MDA concentration/content did not differ from the values of the INT group (Tab 3-5).

Table 1. Effects of BEXA and BEXA+MEL on mammary carcinogenesis parameters.

\begin{tabular}{lccc}
\hline \multirow{2}{*}{ Group } & CONT & BEXA & BEXA+ MEL \\
\cline { 2 - 5 } & $\mathbf{n}=\mathbf{1 6}$ & $\mathbf{n}=\mathbf{1 7}$ & $\mathbf{n}=\mathbf{1 7}$ \\
\hline Tumor incidence (\%) & $75.0 \pm 11.2$ & $58.8 \pm 12.3(-21.6)$ & $\mathbf{2 3 . 6 \pm 1 0 . 6}{ }^{\text {aa }}(-68.5),{ }^{b}[-59.9]$ \\
Tumor frequency per group & $2.44 \pm 0.55$ & $\mathbf{0 . 7 6} \pm \mathbf{0 . 1 8}{ }^{\text {aa }(-68.9)}$ & $\mathbf{0 . 4 7} \pm \mathbf{0 . 2 6}{ }^{\text {aa }}(-80.7),[-38.2]$ \\
Tumor frequency per animal & $3.25 \pm 0.55$ & $1.30 \pm \mathbf{0 . 1 5}{ }^{\text {aa }(-60.0)}$ & $2.00 \pm 0.71(-38.5),[+53.8]$ \\
Tumor volume $\left(\mathrm{cm}^{3}\right)$ & $1.20 \pm 0.35$ & $1.52 \pm 0.61(+26.7)$ & $1.35 \pm 0.70(+12.5),[-11.2]$ \\
Tumor latency (days) & $86.32 \pm 2.94$ & $91.54 \pm 3.91(+6.1)$ & $86.0 \pm 6.28(-0.4),[-6.1]$ \\
\hline
\end{tabular}

Data are expressed as means \pm S.E.M

Significant difference between groups is designated as: ${ }^{\text {a }} \mathrm{P}<0.05$ vs CONT; a $\mathrm{P}<0.01$ vs CONT, values in round brackets are calculated as $\%$-ual deviation from the $100 \%$ of CONT group ; ${ }^{\mathrm{b}} \mathrm{P}<0.05$ vs BEXA; ${ }^{\mathrm{bb}} \mathrm{P}<0.01$ vs BEXA, values in square brackets are calculated as \%-ual deviation from the $100 \%$ of $\mathrm{BEXA}$ group. CONT - control group with NMU, BEXA - BEXA (26.7 ug/g b.w), BEXA+MEL - BEXA (26.7 ug/g b.w) with MEL (20 ug/ml drinking water), n=number of individuals

Table 2. Histopathological classification of mammary tumors

\begin{tabular}{|c|c|c|c|c|}
\hline Malignant lesions - types & CONT & BEXA & BEXA+MEL & $\mathbf{n}$ \\
\hline cribriform & 11 & 2 & 5 & (18) \\
\hline cribriform and papillary carcinoma & 10 & 5 & 1 & $(16)$ \\
\hline papillary carcinoma & 3 & 1 & 1 & $(5)$ \\
\hline cribriform and comedo carcinoma & 5 & - & - & $(5)$ \\
\hline cribriform, papillary carcinoma and comedo & 1 & - & - & $(1)$ \\
\hline Number of malignant lesions & 36 & 11 & 8 & (55) \\
\hline Forms: high to low grade ratio & $21 / 15$ & $4 / 7$ & $3 / 5$ & \\
\hline \multicolumn{5}{|l|}{ Benign tumors } \\
\hline tubular- and fibroadenoma & - & 1 & - & $(1)$ \\
\hline fibrosarcoma & - & 1 & - & $(1)$ \\
\hline Number of benign tumors & - & 2 & - & $(2)$ \\
\hline Total number & 36 & 13 & 8 & $(57)$ \\
\hline
\end{tabular}

The columns indicate the number of tumors in groups. The lines are the numbers of tumor types. Other details: see Tab. 1 
Table 3. Effects of BEXA and BEXA+MEL on selected metabolic parameters in serum.

\begin{tabular}{lcccc}
\hline & INT & CONT & BEXA & BEXA+MEL \\
\hline Serum & & & & \\
GLU $(\mathrm{mmol} / \mathrm{l})$ & $5.01 \pm 0.10$ & $\mathbf{3 . 0 9} \pm \mathbf{0 . 1 3}$ aaa $\{-38.3\}$ & $3.43 \pm 0.14(+11.0)$ & $\mathbf{4 . 3 3} \pm \mathbf{0 . 1 4} \mathbf{c}^{\mathrm{ccc}}(+40.1)$, ddd $[+26.2]$ \\
TAG $(\mathrm{mmol} / \mathrm{l})$ & $0.56 \pm 0.04$ & $0.51 \pm 0.03\{-8.9\}$ & $0.54 \pm 0.043(+5.9)$ & $0.48 \pm 0.03(-5.9),[-11.1]$ \\
CH $(\mathrm{mmol} / \mathrm{l})$ & $3.34 \pm 0.19$ & $3.49 \pm 0.25\{+4.5\}$ & $3.65 \pm 0.17(+4.6)$ & $3.72 \pm 0.15(+6.6),[+1.9]$ \\
PL $(\mathrm{mmol} / \mathrm{l})$ & $1.94 \pm 0.12$ & $1.70 \pm 0.22\{-12.4\}$ & $1.72 \pm 0.11(+2.4)$ & $1.84 \pm 0.11(+8.2),[+5.7]$ \\
CTS $(\mathrm{ng} / \mathrm{ml})$ & $182.05 \pm 34.36$ & $193.21 \pm 21.70\{+6.1\}$ & $246.40 \pm 25.50(+27.5)$ & $166.23 \pm 33.06(-14.0),[-32.5]$ \\
\hline
\end{tabular}

Data are expressed as means \pm S.E.M. Significant difference between groups is designated as: aaa $\mathrm{p}<0.001$ (CONT vs INT), $\mathrm{ccc} p<0.001$ (BEXA + MEL vs CONT), ddd $\mathrm{p}<0.001$ (BEXA + MEL vs BEXA); values in curly brackets are calculated as \%-ual deviation from the $100 \%$ of INT group; values in round brackets are calculated as \%-ual deviation from the $100 \%$ of CONT group, values in square brackets are calculated as \%-ual deviation from the $100 \%$ of BEXA group, GLU - glucose, TAG - triacylglycerols, CH - cholesterol, PL - phospholipids, CTS - corticosterone.

Table 4. Effects of BEXA and BEXA+MEL on selected metabolic parameters in liver.

\begin{tabular}{|c|c|c|c|c|}
\hline & INT & CONT & BEXA & BEXA+MEL \\
\hline \multicolumn{5}{|l|}{ Liver } \\
\hline $\mathrm{TAG}(\mu \mathrm{mol} / \mathrm{g})$ & $18.47 \pm 0.91$ & $15.51 \pm 1.50\{-16.0\}$ & $\mathbf{8 . 8 3} \pm \mathbf{0 . 5 6} 6^{\text {bbb }}(-43.1)$ & $\mathbf{1 0 . 0 7 \pm 0 . 8 4} 4^{\mathrm{cc}}(-35.1),[+14.0]$ \\
\hline TAG $(\mu \mathrm{mol})$ & $134.73 \pm 7.46$ & $\mathbf{9 7 . 4 1} \pm \mathbf{1 0 . 3 6}$ aa $\{-27.7\}$ & $59.45 \pm 3.17$ bbb $(-39.0)$ & $62.53 \pm 5.25^{c c}(-35.8),[+5.2]$ \\
\hline $\mathrm{CH}(\mu \mathrm{mol} / \mathrm{g})$ & $22.66 \pm 0.74$ & $22.40 \pm 1.59\{-1.1\}$ & $18.05 \pm 0.59(-19.4)$ & $18.42 \pm 0.56(-17.8),[+2.0]$ \\
\hline $\mathrm{CH}(\mu \mathrm{mol})$ & $159.59 \pm 5.88$ & $148.33 \pm 9.36\{-7.1\}$ & $121.89 \pm 4.26^{\mathrm{b}}(-17.8)$ & $122.73 \pm 4.53^{c}(-17.3),[+0.7]$ \\
\hline MDA (nmol/g) & $20.22 \pm 2.30$ & $43.24 \pm 3.99$ aаa $\{+113.8\}$ & $26.90 \pm 1.76^{\mathrm{bb}}(-37.8)$ & 19.17 $\pm 2.42 \operatorname{ccc}(-55.7),{ }^{d}[-28.7]$ \\
\hline $\mathrm{PL}(\mu \mathrm{mol} / \mathrm{g})$ & $41.78 \pm 1.38$ & $37.59 \pm 1.46$ a $\{-10.0\}$ & $40.40 \pm 0.86(+7.5)$ & $41.69 \pm 0.77^{c}(+10.9),[+3.2]$ \\
\hline$P L(\mu m o l)$ & $294.03 \pm 14.92$ & $257.38 \pm 10.34\{-12.5\}$ & $282.92 \pm 14.07(+9.9)$ & $281.53 \pm 11.37(+9.4),[-0.5]$ \\
\hline $\mathrm{GLY}(\mu \mathrm{mol} / \mathrm{g})$ & $14.28 \pm 1.28$ & $9.82 \pm 0.71$ a $\{-31.2\}$ & $13.75 \pm 1.93(+40.0)$ & $15.41 \pm 1.28^{c c}(+56.9),[+12.1]$ \\
\hline GLY ( & $107.76 \pm 11.22$ & $70.75 \pm 5.87$ a $\{-34.3\}$ & $104.80 \pm 17.33(+48.1)$ & $102.19 \pm 9.68^{\mathrm{cc}}(+44.4),[-2.5]$ \\
\hline Liver weight (g) & $7.07 \pm 0.19$ & $6.77 \pm 0.28\{-4.24\}$ & $6.79 \pm 0.19(+0.3)$ & $6.68 \pm 0.18(-1.3),[-1.6]$ \\
\hline
\end{tabular}

Data are expressed as means \pm S.E.M. Significant difference between groups is designated as: ${ }^{\text {a }}$ - CONT vs INT $(\mathbf{a} p<0.05 ;$ aa $p<0.01 ;$ aaa $p<0.001) ;{ }^{\text {b }}$ BEXA vs CONT ( $\mathbf{b} \mathrm{p}<0.05 ; \mathbf{b b} \mathrm{p}<0.01$; bbb $\mathrm{p}<0.001)$; ${ }^{\mathrm{c}}-\mathrm{BEXA}+$ MEL vs CONT $(\mathbf{c} \mathrm{p}<0.05 ; \mathbf{c c} \mathrm{p}<0.01 ; \mathbf{c c c} \mathrm{p}<0.001)$; ${ }^{\mathrm{d}}-$ BEXA + MEL vs BEXA (d p $<0.05 ;$ dd $\mathrm{p}<0.01$ ); GLY - glycogen, TAG - triacylglycerols, CH - cholesterol, PL - phospholipids, MDA - malondialdehyde . Other details: see Tab. 3

\section{Discussion}

Inhibitory effect of BEXA in experimental mammary carcinogenesis up to total tumor regression was reported by Gottardis et al. [22] and Bischoff et al. [23]. BEXA was effective also in estrogen receptor-negative tumor prevention in transgenic mice bearing mammary tumors[24]. Lubet et al. [25] and Grubbs et al. [7] focused on dose-dependent BEXA efficacy in NMU-induced rat mammary carcinogenesis. Daily BEXA administration at different concentrations during 120 days decreased mammary tumor frequency per animal by $78-96 \%$ (administration by gavage) or by $38-92 \%$ (administration in the diet), respectively. High BEXA doses prominently reduced proliferation and induced apoptosis in tumor cells with simultaneous serum IGF-1 decrease [25]. Grubbs et al. [7] tested new UAB retinoids and BEXA using the same long-term experimental model but chemoprevention was administered only for 7 days. High doses of BEXA and 4-methyl-UAB30 decreased mammary tumor frequency by $75-80 \%$ with concomitant proliferation decrease and apoptosis induction. As expected, retinoid administration induced dose-proportional triacylglycerol increase [7].
The aim of this study was to use lower BEXA dose in combination with other substance to enhance rexinoid effect on NMU treated rats. A similar approach was used by Bischoff et al. [23] with tamoxifen and Suh et al. [26] with arzoxifen. We also evaluated selected parameters of BEXA metabolic impact. Among other results we proved that the chosen BEXA dose did not increase triacylglycerolemia. NMU administration without chemoprevention (CONT group) significantly decreased glycaemia, TAG and GLY liver content and decreased (nonsignificantly) liver PL and CH content and heart muscle GLY concentration while liver and thymus MDA content was higher in comparison with INT. Preventive-curative BEXA administration decreased liver and thymus MDA accumulation and decreased heart muscle GLY, but reinforced the liver TAG and $\mathrm{CH}$ content decrease. BEXA+MEL combination normalised (to INT level) glycaemia, liver PL, liver and heart muscle GLY, and liver and thymus MDA, liver TAG and CH content remained decreased. Similar changes following NMU administration, particularly liver TAG content decrease in tumor-non-bearing and tumor-bearing female rats in the same experimental mammary carcinogenesis protocol were reported by Chamilová et al. $[9,10]$. They used raloxifen and 
Table 5. Effects of BEXA and BEXA+MEL on glycogen and malondialdehyde in heart muscle and thymus.

\begin{tabular}{|c|c|c|c|c|}
\hline & INT & CONT & BEXA & BEXA+MEL \\
\hline \multicolumn{5}{|l|}{ Heart muscle } \\
\hline GLY $(\mu \mathrm{mol} / \mathrm{g})$ & $7.13 \pm 0.67$ & $5.53 \pm 0.56\{-22.4\}$ & $7.03 \pm 0.54(+27.1)$ & $\mathbf{7 . 6 9} \pm \mathbf{0 . 6 6 ^ { c }}(+39.1),[+9.4]$ \\
\hline GLY $(\mu \mathrm{mol})$ & $5.44 \pm 0.52$ & $4.16 \pm 0.37\{-23.5\}$ & $5.14 \pm 0.48(+23.6)$ & $5.85 \pm 0.66(+40.6),[+13.8]$ \\
\hline Weight (g) & $766.63 \pm 18.43$ & $717.00 \pm 28.30\{-6.5\}$ & $725.41 \pm 22.25(+1.2)$ & $717.77 \pm 15.21(+0.1),[-1.1]$ \\
\hline \multicolumn{5}{|l|}{ Thymus } \\
\hline $\mathrm{MDA}(\mathrm{nmol} / \mathrm{g})$ & $15.25 \pm 0.60$ & $20.36 \pm 1.49$ a $\{+33.5\}$ & $18.63 \pm 0.92(-8.5)$ & $\mathbf{1 6 . 2 7} \pm \mathbf{0 . 6 0}{ }^{\mathrm{c}}(-20.1),{ }^{\mathrm{d}}[-12.7]$ \\
\hline MDA (nmol) & $2.91 \pm 0.12$ & $3.58 \pm 0.27\{+23.0\}$ & $3.23 \pm 0.24(-9.8)$ & $\mathbf{2 . 8 5} \pm \mathbf{0 . 2 0}{ }^{\mathrm{c}}(-20.4),[-11.8]$ \\
\hline Weight (g) & $198.11 \pm 8.77$ & $174.25 \pm 12.54\{-12.0\}$ & $168.72 \pm 11.67(-3.2)$ & $177.29 \pm 12.38(+1.7),[+5.1]$ \\
\hline
\end{tabular}

Data are expressed as means \pm S.E.M. Significant difference between groups is designated as: a $p<0.05$ (CONT vs INT), $\mathbf{c} p<0.05$ (BEXA + MEL vs CONT), d p $<0.05$ (BEXA + MEL vs BEXA); GLY - glycogen, MDA - malondialdehyde . Other details: see Tab. 3

tamoxifen, in combination with MEL as chemopreventives and, similarly to our results, chemoprevention did not alleviate lipid metabolism disturbances. We assume this is a result of decreased lipogenesis following carcinogen administration and cancer progression. No macroscopic/microscopic liver lesions were found. We confirmed MEL efficacy as "co-chemopreventive" substance, possibly as ROS scavenger [27] which was demonstrated by attenuated tissue MDA formation.

To summarize, lower dose of the rexinoid BEXA alleviated the carcinogen-induced metabolic changes and the combination with other substance MEL enhanced its preventive - curative action in experimental mammary carcinogenesis. Since MEL has been shown to enhance the chemopreventive efficacy of celecoxib in the same model previously [28], the combination of BEXA plus MEL may be considered in oncological practice too.

Acknowledgments: The experiment was supported by Grant Agency of Faculty of Education, Catholic University in Ružomberok.

\section{References}

[1] MOON RC, Grubbs CJ, Sporn MB. Inhibition of 7,12dimetylbenz(a)anthracene-induced mammary carcinogenesis by retinyl acetate. Cancer Res 1976; 36: 2626-2630.

[2] AHLERSOVA E, AHLERS I, KUBATKA P, BOJKOVA B, MOCIKOVA $K$ et al. Melatonin and retinyl acetate as chemopreventives in DMBA-induced mammary carcinogenesis in female Sprague-Dawley rats. Folia Biol (Prague) 2000; 46: 69-72.

[3] BOJKOVA B, KUBATKA P, MOCIKOVA K, MNICHOVA M, AHLERSOVA E et al. Effects of retinyl acetate and melatonin on N-methyl-N-nitrosourea-induced mammary carcinogenesis in rats. A preliminary report. Folia Biol (Prague) 2000; 46: $73-76$.

[4] MOON RC, MEHTA RG, DETRISAC CJ. Retinoids as chemopreventive agents for breast cancer. Cancer Detect Prevent 1992; 16: 73-80.

[5] DRAGNEV HD, RIGAS JR, DMITROVSKY E. The retinoids and cancer prevention mechanisms. Oncologist 2000; 5: 361-368. http: //dx.doi.org/10.1634/theoncologist.5-5-361
[6] WONG SF. Oral bexarotene in the treatment of cutaneous T-cell lymphoma. Ann Pharmacother 2001; 35: 1056-1065. http: //dx.doi.org/10.1345/aph.10223

[7] GRUBBS CJ, LUBET RA, ATIGADDA VR, CHRISTOV $\mathrm{K}, \mathrm{DESHPANDE}$ AM et al. Efficacy of new retinoids in the prevention of mammary cancers and correlations with shortterm biomarkers. Carcinogenesis 2006; 27: 1232-1239. http: //dx.doi.org/10.1093/carcin/bgi308

[8] QU L, TANG X. Bexarotene: a promising anticancer agent. Cancer Chemother Pharmacol 2010; 65: 201-205. http: //dx.doi.org/10.1007/s00280-009-1140-4

[9] CHAMILOVA M, BOJKOVA B, KUBATKA P, KALICKA $\mathrm{K}$, ADAMEKOVA E, et al. Prevention of N-methyl-N-nitrosourea-induced mammary carcinogenesis in female rats by tamoxifen and melatonin: metabolic alterations. Biologia (Bratislava) 2001; 56: 565-571.

[10] CHAMILOVA M, KUBATKA P, KALICKA K, ADAMEKOVA E, BOJKOVA B, et al. Chemoprevention of N-methyl-N-nitrosourea induced mammary carcinogenesis with raloxifene and melatonin: Metabolic changes in female rats. Acta Vet (Brno) 2002; 71: 235-242. http: //dx.doi.org/10.2754/avb200271020235

[11] LELBACH A, MUZES G, FEFER J. Current perspectives of catabolic mediators of cancer cachexia. Med Sci Monit 2007; 13: $168-173$.

[12] BLASK DE, SAUER LA, DAUCHY RT, HOLOWACHUK EW, RUHOFF MS et al. Melatonin inhibition of cancer growth in vivo involves suppression of tumor fatty acid metabolism via melatonin receptor-mediated signal transduction events. Cancer Res 1999; 59: 4693-4701.

[13] ANISIMOV VN. The role of pineal gland in breast cancer development. Crit Rev Oncol Hematol 2003; 46: 221-234. http: //dx.doi.org/10.1016/S1040-8428(03)00021-0

[14] COS S, SANCHEZ-BARCELO EJ. Melatonin and mammary pathological growth. Front Neuroendocrinol 2000; 21 : 133-170. http: //dx.doi.org/10.1006/frne.1999.0194

[15] LISSONI P, PAOLOROSSI F, TANCINI G, BARNI S, ARDIZZOIA A et al. Is there a role for melatonin in the treatment of neoplastic cachexia? Eur J Cancer 1996; 32: 1340-1343. http: //dx.doi.org/10.1016/0959-8049(96)00136-0

[16] RUSSO J, RUSSO IH. Atlas and histologic classification of tumor of the rat mammary gland. J Mammary Gland Biol 
Neoplasia 2000; 5: 187-200. http: //dx.doi.org/10.1023/A: 1026443305758

[17] BARTLETT GR. Phosphorus assay in column chromatography. Biol Chem 1959; 234: 466-468.

[18] ZLATKIS A, ZAK B, BOYLE AJ. A new method for the direct determination of cholesterol. J Lab Clin Med 1953; 41: 486-490.

[19] ROE JH, DAILEY R. The determination of glycogen with anthrone reagent. Analyt Biochem 1966; 15: 245-250. http: //dx.doi.org/10.1016/0003-2697(66)90028-5

[20] SATOH K. Serum lipid peroxide in cerebrovascular disorders determined by a new colorimetric method. Clin Chim Acta 1978; 90: 37-43. http: //dx.doi.org/10.1016/00098981(78)90081-5

[21] GUILLEMIN R, CLAYTON GW, SMITH JD, LIPSCOMB HS. Measurement of free corticosteroids in rat plasma: physiological validation of method. Endocrinology 1958; 63: 349-357. http: //dx.doi.org/10.1210/endo-63-3-349

[22] GOTTARDIS MM, BISCHOFF ED, SHIRLEY MA, WAGONER MA, LAMPH WW et al. Chemoprevention of mammary carcinoma by LGD 1069 (Targretin): an selective ligand. Cancer Res 1996; 56: 5566-5570.

[23] BISCHOFF ED, GOTTARDIS MM, MOON TE, HEYMAN RA; Lamph WW. Beyond tamoxifen: the retinoid $\mathrm{X}$ receptor selective ligand LGD 1069 (TARGRETIN) causes complete regression of mammary carcinoma. Cancer Res 1998; 58: 479-484.

[24] WU K, ZHANG Y, XU XC, HILL J, CELESTINO J et al. The retinoid X receptor-selective retinoid, LGD1069, prevents the development of estrogen receptor-negative mammary tumors in transgenic mice. Cancer Res 2002; 62: 6376-6380.

[25] LUBET RA, CHRISTOV K, NUNEZ NP, HURSTING SD, STEELE VE et al. Efficacy of Targretin in methylnitrosourea-induced mammary cancers: prevention and therapy dose-response curves and effects on proliferation and apoptosis. Carcinogenesis 2005; 26: 441-448. http: //dx.doi.org/10.1093/carcin/bgh338

[26] SUH N, LAMPH WW, GLASEBROOK AL, GRESE TA, PALKOWITZ AD et al. Prevention and treatment of experimental breast cancer with the combination of a new selective estrogen receptor modulator, arzoxifene, and a new rexinoid, LG 100268. Clin Cancer Res 2002; 8: 3270-3275.

[27] TAN DX, HARDELAND R, MANCHESTER LC, PAREDES SD, KORKMAZ A et al. The changing biological roles of melatonin in evolution: from an antioxidant to signals of dakness, sexual selection and fitness. Biol Rev Camb Philos Soc 2010; 85: 607-623.

[28] ORENDAS P, KASSAYOVA M, KAJO K, AHLERS I, KUBATKA $P$ et al. Celecoxib and melatonin in prevention of female rat mammary carcinogenesis. Neoplasma 2009; 56: 250-256. http: //dx.doi.org/10.4149/neo $2009 \quad 03 \quad 252$ 